\title{
Osteopetrosis in cathepsin K-deficient mice
}

\author{
Lorenz C Hofbauer and Armin E Heufelder ${ }^{1}$ \\ Endocrine Research Unit, Mayo Clinic, Rochester, Minnesota 55905, USA and ${ }^{1}$ Endocrine Research Unit, Zentrum für Innere Medizin, \\ Phillips-University, 35033 Marburg, Germany
}

(Correspondence should be addressed to LC Hofbauer; Email: heufelderae@mailer.uni-marburg.de)

Osteopetrosis is a fascinating, inherited polygenic disorder of bone metabolism characterized by a generalized increase in bone mass due to decreased bone resorption (1). While it is relatively rare, it provides important clues to the understanding of bone cell biology and the pathogenesis of metabolic bone diseases. Since osteopetrosis results from decreased osteoclastic bone resorption, its molecular and cellular etiology is intriguing with respect to the pathogenesis of osteoporosis, which is generally characterized by increased osteoclastic bone resorption. Thus, identification of the defects leading to osteopetrosis may allow design of a causative, cell biology-based therapeutic approach for osteoporosis.

Thus far, most animal models of osteopetrosis have been the result of spontaneous or experimental deletion of cytokines required for osteoclastogenesis, such as osteoprotegerin ligand $(2,3)$, macrophage colonystimulating factor (4), or their respective down-stream signaling molecules, including NF- $\kappa \mathrm{B}$ (5), PU.1 (6) and c-fos $(7,8)$. These associated phenotypes are due to the disruption of osteoclast differentiation from pluripotent osteoclast precursor cells, and are variably combined with hematological or immunological abnormalities, indicating the pleiotropic nature of these cytokines.

Saftig and associates (9) have now identified cathepsin K-deficiency as yet another cause for osteopetrosis. Cathepsin K, a member of the papain-cysteine protease family, is an enzyme that is abundantly and selectively produced by osteoclasts. Its major effects in the process of osteoclastic bone resorption include degradation of the bone matrix proteins osteopontin, osteonectin and collagen types I and II at an acidic $\mathrm{pH}$. A mutation of the human cathepsin $\mathrm{K}$ gene has recently been linked to human pycnodysostosis, which is an osteopetrotic disorder of variable severity and associated abnormalities, including short stature, dysplasia of membranous bones (clavicle, skull) and acroosteolysis of the distal phalanges (10).

Analysis of cathepsin K knock-out mice revealed viable and fertile offspring without obvious malformations or abnormalities until the age of 10 months (9). The most striking feature in homozygous littermates was the presence of dense, thick trabeculae, which were most prevalent in rapidly growing areas of endochondral ossification and spared the membranous bone areas, as assessed by radiological analysis. Scanning electron microscopy revealed the retention of cancellous bone and the presence of thick trabeculae in cathepsin K-deficient mice. Histological studies confirmed these findings and showed that marrow cavities contained large amounts of primary unresorbed spongiosa; however, hematopoiesis was normal in cathepsin K-deficient mice, which is in contrast to other animal models of osteopetrosis. Of note, cathepsin K-deficient mice had intact epiphyseal and vertebral growth plates and normal longitudinal bone growth (9). Ultrastructural analysis of cathepsin K-deficient osteoclasts revealed signs of decreased proteolytic activity. Finally, cathepsin K-deficient osteoclasts, when tested for their functional activity on dentine slices, produced fewer resorption pits with a lower pit volume and depth compared with wild-type osteoclasts (9). Collectively, these data clearly confirm that cathepsin $\mathrm{K}$ is essential for osteoclastic resorption of bone matrix.

In contrast to other forms of osteopetrosis, which are due to disrupted osteoclastogenesis, cathepsin K-deficiency is associated with an inhibition of osteoclast activity. Similar effects have also been reported for targeted ablation of proto-oncogenes such as c-src $(11,12)$ and c-cbl (13). As a result of high and specific osteoclastic expression, cathepsin K deficiency specifically targets osteoclasts while not interfering with immune cell function or hematopoiesis. Conceptually, it therefore seems possible to use cathepsin $\mathrm{K}$ protease inhibitors to inhibit increased osteoclastic activity in patients with osteoporosis due to glucocorticoid excess, estrogen deficiency, rheumatoid arthritis or hypercalcemia of malignancy. Clinical studies will tell us more...

\section{References}

1 Felix R, Hofstetter W \& Cecchini MG. Recent developments on the understanding of the pathophysiology of osteopetrosis. European Journal of Endocrinology 1996134 143-156.

2 Simonet WS, Lacey DL, Dunstan CR, Kelley M, Chang M-S, Lüthy R et al. Osteoprotegerin: a novel secreted protein involved in the regulation of bone density. Cell 199789 309-319.

3 Boyle WJ, Kung Y, Lacey DL, Sarosi I, Dunstan CR, Timms E et al. Osteoprotegerin ligand (OPGL) is required for murine osteoclastogenesis. Bone 199823 (Suppl 1) S189. 
4 Yoshida H, Hayashi S, Kunisada T, Ogawa M, Nishikawa S, Okamura $\mathrm{H}$ et al. The murine mutation osteopetrosis is in the coding region of the macrophage colony stimulating factor gene. Nature $1990345442-444$.

5 Iotsova V, Caamano J, Loy J, Yang Y, Lewin A \& Bravo R. Osteopetrosis in mice lacking NF-kB1 and NF-kB2. Nature Medicine 19983 1285-1289.

6 Tondravi MM, McKercher SR, Anderson K, Erdmann JM, Quiroz M, Maki R et al. Osteopetrosis in mice lacking haemapoietic transcription factor PU.1. Science 1997386 81-84.

7 Wang ZQ, Ovitt C, Grigoriadis AE, Mohle-Steinlein U, Ruther U \& Wagner EF. Bone and hematopoietic defects in mice lacking c-fos. Nature $1992360741-745$.

8 Johnson RS, Spiegelman BM \& Papaioannou V. Pleiotropic effects of a null mutation in the c-fos proto-oncogene. Cell 1992 71 577-586.

9 Saftig P, Hunziker E, Wehmeyer O, Jones S, Boyde A, Rommerskirch W et al. Impaired osteoclastic bone resorption leads to osteopetrosis in cathepsin K-deficient mice. Proceedings of the National Academy of Sciences of the USA 199895 13453-13458.

10 Gelb BD, Shi GP, Chapman HA \& Desnick RJ. Pycnodysostosis, a lysosomal disease caused by cathepsin K deficiency. Science 1996 273 1236-1238.

11 Soriano P, Montgomery C, Geske R \& Bradley A. Targeted disruption of the c-src proto-oncogene leads to osteopetrosis in mice. Cell $199164693-702$.

12 Teti A, Taranta A, Migliaccio S, Degiorgi A, Santandrea E, Villanova I et al. Colony stimulating factor-1-induced osteoclast spreading depends on substrate and requires the vitronectin receptor and the c-src proto-oncogene. Journal of Bone and Mineral Research 199812 50-58.

13 Tanaka S, Amling M, Neff L, Peyman A, Uhlmann E, Levy JB et al. $\mathrm{c}-\mathrm{Cbl}$ is downstream of c-Src in signalling pathway necessary for bone resorption. Nature 1996383 528-531. 